läufer der Gefässbildung zu sein scheinen. Ich glaube, man muss sie ebenfalis als endogene aus ursprünglichen Kernwucherungen hervorgegangene Gebilde betrachten. An der Oberfläche der fraglichen beiden Hornhäute, wo, wie gesagt, diese Zellstränge ein dichtes Netz bildeten, fehlte die Bowmanssche Membran gänzlich. Besonders merkwürdig erschien mir eine Stelle, wo ein solcher dicker Strang an der Oberfläche gleichsam einmündete; und in dieser Mändung kolbige Zellen den Uebergang zum Ejitheliam der übrigen Fläche bildeten.

Die Hornhautkörperchen im Umfang der Narben zeigen im Uebrigen sehr deutliche, aher nicht gewucherte Kerne, dagegen sind sie mit Fetttröpfchen verschiedenen Calibers versehen.

Nachträglich muss iclı bemerken, dass ich in den Fällen 1, 4 und $\mathbf{5}$ auch die Conjunctiva mit grossen Kernmassen durchsetzt fand, über deren näheres Verhalten ich mich aher aus Mangel an Zeit noch nicht umgethan habe.

Ich füge noch eine Beobachtung bei, die ich an der Linse gemacht babe, da ich nicht weiss, ob sie schon anderweitig gemacht ist: Es betrifft einen sogenannten weichen Staar bei einem an Diabetes mellit. verstorbenen Individum:

Rinden - und Kernsubstanz waren geträbt, erstere in Segmente zerfallen und leicht abhebbar. Es fand sich nun, dass die Fasern der Rindensubstanz sämmtlich mit reichlichen randständigen Kernen verseben waren, die dadurch, dass sie in verschiedenen Lagen sich deckten, die Masse ganz undurchsichtig machten. Im Linsenkern fanden sich in den Fasern statt dieser Kerne und an den entsprechenden Stellen kleine Conglomerate von Fetttröpfehen, die von keiner Membran mehr umschlossen waren, aber durch eine hindende Masse zusammenhingen. Die übrigen Röhren waren frei.

3.

\title{
Ueber das Vorkommen von krystallinischen Kalksalzen in ossificirenden Geschwülsten.
}

\author{
Von Dr. C. O. Weber in Bonn.
}

$\mathbf{B}_{e i}$ Enchondromen und ähnlichen wuchernden Gebilden sain ich üherstürzte Einlagerung von Knochenerde in das Bindegewebe, die neben der Verknöcherung des Gewebes manchmal in unmittelbarer Nähe vorkommt, so dass es aussieht, als ob, sit venia verbo, die Natur nicht Zeit gehabł hätte, die in übergrosser Menge herbeigeführten Kalksalze in die Gewebe zu verarbeiten, so dass die überschüssigen nun nicht einmal ganz amorph zwischengelagert und allmählig zu dicken, grossen (sandigen) Concrementen sich anhäufen. Besonders habe ich dies beobachtet in einem Bindegewebsprodukte eines von Herrn Wutzer resecirten Unterkiefers, sowie in einem Enchondrom der ersten Phalanx eines Zeigefingers. Die

Archiv f, pathol. Anat. Bd. Vl. Heft 4 . 
Kalkerde wird hier neben regelrechter Verknöcherung in Form rhomhischer Körnchen zwischengelagert. Diese vergrössern sich und erscheinen dann in zu unregelınässigen Haufen zusammengehackenen krystallinischen ziemlich grossen förnern, an denen man hin und wieder die rhombische Tafel noch wahnelumen kann. Von Cholestearintafeln durch geringere Durchsichtigkeit, weniger ansgebildete Form, grössere Masse oder Dicke und andere Winkel deutlich verschieden, verwandeln sich diese lrrystallinischen Haufen, ohne Entwicklung ron Kohlensäure, beim Zusatze ron Schwefelsäure in scböne Gypskrystalle; sie sind also wahrscheinlich phosphorsaurer Kalk, wie auch die Vergleichnng mit künstlich dargestelltem phosphorsauren Kalke zeigt.

Zusatz des Herausgebers. Ich sah krystallinische Gebilde, wie sie Herr Weber beschreibt, hauptsächlich in der Nähe ossificirender Stellen der Intervertehralknorpel, war aber mehr geneigt, sie als kohlensauren Kalk anzusprechen, worauf ihre Krystallform hinzudeuten schien. Die mikrochemische Reaction ist hier insofern nicht entscheidend, als bei geringen Mengen koblensaurer Salze ein Freiwerden der Kollensäure bei der Einwirkung von Säuren nicht immer geschieht, indem sich dieselbe sofort in den Flüssigkeiten löst. Bei Enchondromen hatte ich bis jetzt nicht Gelegenheit, etwas Aehnliches zu sehen; nur in einer verwandten Geschwulst, die ich früher kurz beschrieh (dies. Archiv Bd.V. S. 241.), traf ich zwiebackförmige Körper, die viel Uebereinstimmung mit Kernen des Kalkcarbonats zeigten. Nicht seiten finden sich auch Gebilde dieser Art im Knochenmark, aus dem sie schon Hr. Rheiner (Beiträge zur Histologie des Kehlkopfs. Inaug. Abh. Würzburg 1852. S. 29.) besclurieben hat.

Rud. Virchow.

4.

\title{
Ueber das ausgebreitete Vorkommen einer dem Nerven- mark analogen Substanz in den thierischen Geweben.
}

Von Rud. Vircbow.

\begin{abstract}
Schon seit einer Reihe von Jahren wurde meine Aufmerksamkeit bei der Untersuchung kranker Lnngentheile auf das Vorkommen einer eigenthümlichen Substanz gerichtet, welche sich namentlich in den ausgepressten oder abgeschabten Massen vorfand und welche die grösste morphologische Uehereinstimmung mit ausgetretenem Nerveninhalte darbot. Obwohl nicht selten diese Substanz in so grosser Quantität vorkam, dass schon dadurch der Gedanke, dass sie aus den Lungennerven abstamme, zurückgewiesen zu werden schien, so verfolgte ich doch diese Möglichkeit genauer. Allein ich war nicht im Stande, die Quelle zu entdecken;
\end{abstract}

